\title{
Comparison of 8-year knee osteoarthritis progression in 2 siblings: a case-based review
}

\author{
Margaret L. Gourlay ${ }^{1,2}$ (D) Linda L. Gourlay ${ }^{3,4}$ \\ Received: 25 March 2020 / Revised: 12 May 2020 / Accepted: 15 May 2020 / Published online: 26 May 2020 \\ (C) The Author(s) 2020, corrected publication 2020
}

\begin{abstract}
Because the pathophysiology of knee osteoarthritis is poorly understood, optimal evidence-based clinical management is uncertain. Sibling comparison studies can help inform a clinical model to guide preventive care. We compared the 8-year clinical outcomes in 2 sisters with a family history of osteoarthritis, normal BMI, and absence of knee pain at baseline. Both patients had Kellgren-Lawrence grade 1 in the affected knee at the time of twisting knee injuries leading to osteoarthritis diagnoses at age 50 (patient 1) and 51 (patient 2). Patient 1 developed a chronic right knee effusion, and progressed to Kellgren-Lawrence grade 3 bilaterally by the time she had a right total knee replacement at age 58. Patient 2 had subchondral fractures of the right knee with transient effusion, which healed after 1 year of partial weight-bearing with crutches and subsequent daily use of knee sleeves. Patient 2 had Kellgren-Lawrence grade 0 bilaterally upon surveillance imaging at age 58 . The terms "osteoarthritis and knee and diagnostic imaging and subchondral bone and pathophysiology" were searched in the PubMed database to identify original research articles to inform a clinical model consistent with the patients' outcomes. A fluid model of osteoarthritis was the best explanatory model for the discordant clinical trajectories of the age-matched siblings. Patient recommendations are presented based on these findings.
\end{abstract}

Keywords Cartilage, articular · Diagnostic imaging · Disease progression · Osteoarthritis, knee/physiopathology

\section{Introduction}

Patients with knee osteoarthritis $(\mathrm{OA})$ are treated conservatively until disease severity warrants joint replacement. While evidence evolves regarding OA pathophysiology and an optimal treatment regimen, sibling comparison studies can

Electronic supplementary material The online version of this article (https://doi.org/10.1007/s10067-020-05181-6) contains supplementary material, which is available to authorized users.

Margaret L. Gourlay

margaret_gourlay@med.unc.edu

Boston Scientific Corporation, Marlborough, MA, USA

2 Department of Family Medicine, University of North Carolina, Chapel Hill, Manning Drive, CB \#7595, Chapel Hill, NC 27599-7595, USA

3 College of Nursing, University of Massachusetts, Amherst, MA, USA

4 Department of Psychiatry, Baystate Medical Center, Springfield, MA, USA provide useful historical and practical clinical information for patients and clinicians. This report documents the medical history of knee OA in 2 sisters with divergent clinical courses. A literature search was conducted to explain the patients' knee OA progression in the context of current data and to inform a clinical model to guide recommendations for patients.

\section{Case presentations}

\section{Family history}

The patients' father (age 91 years, an only child) has obesity, hypertension, chronic kidney disease, and bilateral knee osteoarthritis with a history of bilateral knee replacements in his $80 \mathrm{~s}$. The patients' paternal grandfather rubbed salve on his knees for pain relief, and their paternal grandmother had a postpartum exacerbation of hand arthritis in her early 30s for which she saw a subspecialist physician. The patients' mother (age 91) has normal body weight, osteoporosis, and osteoarthritis and is wheelchair-bound after 2 strokes. 


\section{Patient 1: 59-year-old woman with rapidly progres- sive bilateral knee $O A$}

\section{History}

Patient 1 is a dual-certified psychiatric-mental health nurse practitioner and family nurse practitioner who has worked in academic medical and psychiatric clinical practice for 33 years. She had one child at 39 years of age. Before menopause, she participated in activities such as hiking, exercises with weights, and wearing fashion boots with 1-inch heels without pain. She has lived in 2-story houses with daily stairclimbing for a cumulative 38 years.

Patient 1's onset of chronic knee pain began during perimenopause at age 50 . She was seen by an orthopedic surgeon because of pain and an intermittent sharp catching sensation in her anterior left knee. Physical examination findings included height 5' 5", weight 136 pounds (BMI 22.6), left knee range of motion $0-130^{\circ}$ with crepitus throughout femoral joint, 1+ effusion, and medial joint line tenderness. Radiographs showed the left knee with mild narrowing of the medial joint space compared with the right knee and slight malalignment of the patellofemoral joint (Fig. 1a). She was diagnosed with patellofemoral osteoarthritis and medial meniscus tears of the left knee later confirmed on magnetic resonance imaging (MRI).

Over the subsequent 2 years, patient 1 had 2 arthroscopic examinations with cartilage trimming - first of the left knee and later of the right knee after she tripped and fell onto a mat. At age 52, patient 1 developed a chronic right knee effusion after she stepped off a bus and her knee twisted and buckled during touchdown in a gravel parking lot. Her bilateral knee pain steadily progressed during subsequent years, and she noted increasing varus deformity of both knees. By age 58, radiographs showed definite narrowing of the right and left knee joint spaces (Kellgren-Lawrence grade 3; Fig. 1b). Patient 1's knee pain was worse in the right knee. She had exacerbation of pain when weight-bearing and increased pain and a sensation of pressure during prolonged sitting, making her unable to tolerate long car rides.

\section{Treatment}

Patient 1 received various treatments including nonsteroidal anti-inflammatory agents, topical lidocaine patches, corticosteroid injections, viscosupplementation, knee braces (offloader and sleeve braces), and physical therapy. Based on her worsening pain and increasing frequency of near falls, her orthopedist recommended bilateral total knee replacement. She underwent a right total knee replacement at age 58. After in-home physical therapy for 4 weeks, she attended weekly outpatient physical therapy appointments for 2 months. She then returned to clinical practice and reports good healing of the right knee (pain-free) and persistent left knee pain that is continuous during weight-bearing and resolves when nonweight-bearing. She hopes to defer a left total knee replacement as long as possible.

At age 50, patient 1 was diagnosed with mild vitamin D deficiency (serum 25-OH vitamin D $15.0 \mathrm{ng} / \mathrm{ml}$ ). After 3 months of supplementation, she was vitamin D replete
Fig. 1 Bilateral anterior-posterior knee radiographs for patient 1 at age 50 (a) and age 58 (b), and for patient 2 at age 51 (c) [@ 2015 BMJ Publishing Group Ltd. All rights reserved.] and age 58 (d)
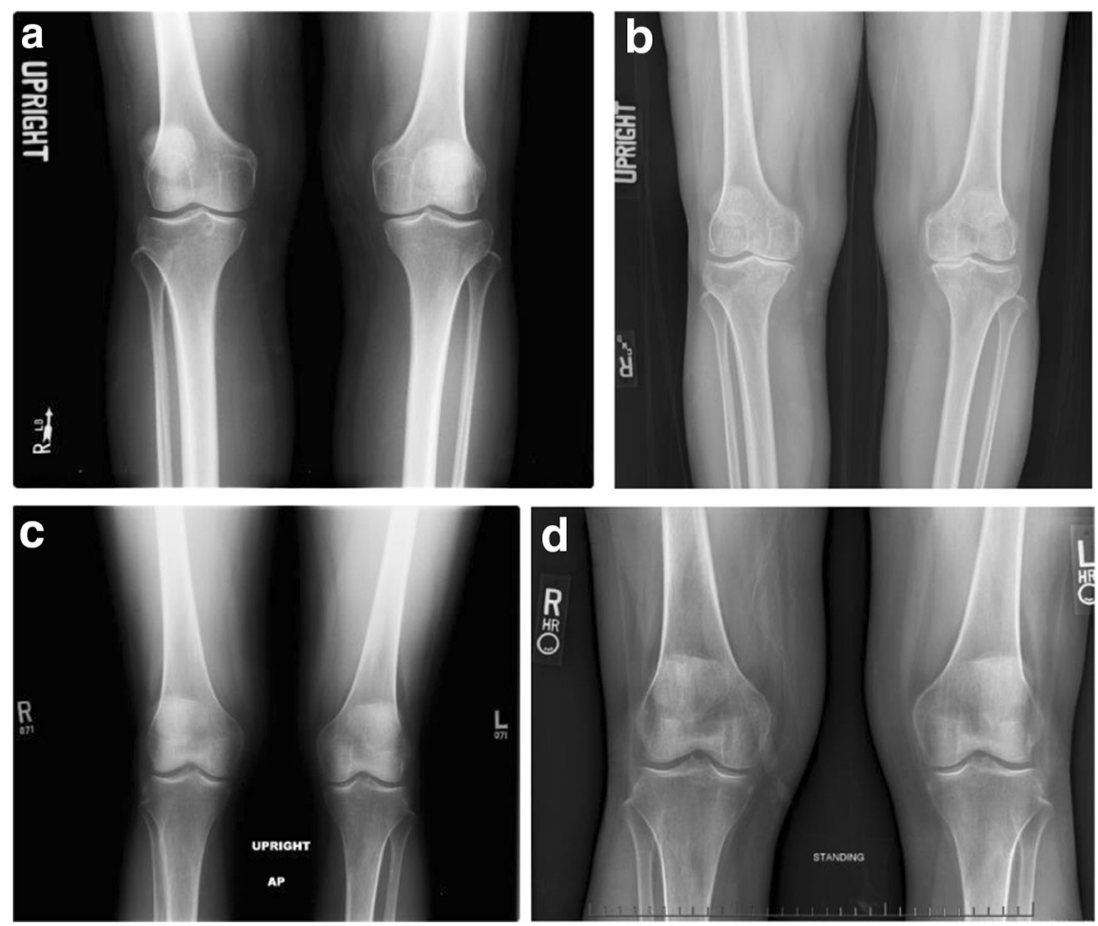
(serum 25-OH vitamin D $44.5 \mathrm{ng} / \mathrm{ml}$ ). She eventually stopped taking supplements and was not tested again until age 59, when she was found to be severely vitamin D-deficient (serum $25-\mathrm{OH}$ vitamin $\mathrm{D} 8.2 \mathrm{ng} / \mathrm{ml}$ ) during a workup for bone density loss in her mandible. A dual-energy x-ray absorptiometry (DXA) bone density test revealed osteopenia, with the lowest $T$ score -2.3 at the femoral neck.

\section{Patient 2: 58-year-old woman with mild knee $O A$ and hand $O A$}

\section{History}

Patient 2 is a family physician who practiced outpatient and inpatient primary care medicine for 15 years. She has a history of pes planus, valgus deformity of the knees for which she consciously torqued her ankles outward to normalize knee alignment since childhood, and osteoporosis diagnosed in her late 30 s (lowest $T$ score -3.0 at the lumbar spine). She has lived in ground-level housing for a cumulative 55 years ( 3 years in apartments or houses with stairs). Between ages 40 and 50, she enjoyed walking 4 miles per day, several times per week.

At age 51 ( 7 months after her last menstrual period), patient 2 had new onset of knee pain after very prolonged standing and a twisting injury to her right knee while exiting an elevator during an 18-h hospital shift. Physical examination 2 months later showed height 5' 7", weight 125 pounds (BMI 19.5), and tenderness to palpation at the right knee lateral joint line and femoral condyle. Radiographs showed a small right knee effusion and minimal osteophytosis with no joint space narrowing (Kellgren-Lawrence grade 1 (right) and grade 0 (left); Fig. 1c), while MRI revealed 2 small subchondral insufficiency fractures at the right lateral femoral condyle with a large amount of associated marrow edema, and a complex, predominantly horizontal tear involving the posterior horn of the medial meniscus. Immediately after the fractures, she felt constant right knee pain (while weight-bearing or nonweightbearing) with increased pain upon weight-bearing, and a sensation of increasing pressure and pain while sitting with her right leg in a dependent position. She was treated with partial weight-bearing on crutches until 14 months after the injury, viscosupplementation at 4 months, and teriparatide treatment to improve bone healing at 7 months. Her clinical course through 2015 is published separately as a case report [1].

Since 2015 , patient 2 has walked independently with the use of bilateral elasticized knee sleeves at all times outside her home and most of the time within the home. Although physical therapists discouraged the use of knee sleeves because they might promote muscle weakness, patient 2 considered published evidence [2-5] and reasoned that wearing the sleeves would increase her muscle strength long-term by enabling her to walk more often. When walking without knee sleeves, she experiences numbness, transient sharp pains and a sensation of walking on an unhealed wound, especially at the right posterolateral tibial plateau where the subchondral fractures occurred. She has minimal knee pain while sleeping on her back but aching and numbness when her knee bones shift as she lies on either side. At age 56, she moved out of state for caregiving responsibilities lasting 6 months. At age 57, she began full-time work as a medical writer for industry, having full control of periods of sitting and standing.

Also since 2015, patient 2 experienced sharp, reversible pain in the distal interphalangeal (DIP) and proximal interphalangeal (PIP) joints during prolonged periods of typing, sometimes followed by soreness that persists for hours after typing. However, prolonged periods of rest from typing during holidays, and sleeping on her side with her head resting on her hands, also led to hand puffiness and pain. At age 58, she consulted her primary care physician, who ordered serology and radiographs. Serology revealed positive ANA and anticentromere B antibody tests, hand radiographs showed periarticular lucencies bilaterally without bony erosions, and surveillance knee radiographs showed preserved joint spaces (Kellgren-Lawrence grade 0 bilaterally; Fig. 1d). A referral rheumatologist documented her clinical diagnosis as inconsistent with inflammatory osteoarthritis, concluding the ANA result was false-positive.

\section{Treatment}

In addition to daily use of knee sleeves bilaterally, patient 2 uses cold packs on her knees, diclofenac 1\% topical (especially for hands) daily, and oral magnesium salicylate or meloxicam $15 \mathrm{mg}$ as needed, usually less than once daily. She uses a gaming computer keyboard with cherry-red MX keys (lowest level of resistance) for all typing and voice dictation software for longer documents. She wears crafter's gloves while typing, sometimes using painter's tape to stabilize the PIP and DIP joints.

\section{Comparison of clinical trajectories}

Characteristics of patient 1 and patient 2 are summarized in Table 1. Differences include a higher BMI, longer period of knee effusion, much longer cumulative daily stairclimbing, vitamin D deficiency, much less use of knee sleeves, and absence of hand pain in patient 1 compared with patient 2 . Patient 1's knee radiographs evolved from KellgrenLawrence grade 1 (right) and grade 0 (left) (Fig. 1a) to grade 3 bilaterally (Fig. 1b) by 8 years post-injury, while patient 2's knee radiographs showed Kellgren-Lawrence grade 1 (right) and grade 0 (left) at the time of her right subchondral fractures (Fig. 1c) and grade 0 bilaterally at 7 years post-injury (Fig. 1d). In both patients, symptomatology correlated with imaging markers of fluid (effusion and bone marrow edema) and 
Table 1 Characteristics of patient 1 (rapidly progressive knee OA) and patient 2 (stable knee OA)

\begin{tabular}{lll}
\hline Characteristic & Patient 1 & Patient 2 \\
\hline BMI at age 50-51 years & 22.6 & 19.5 \\
BMI at age 58 & 24.8 & 20.2 \\
Knee joint alignment & Varus & Valgus \\
Parity & 1 child & Nulliparous \\
Twisting knee injuries & 2 & 1 \\
Knee effusion (cumulative years) & 8 & $<1$ \\
Hand pain & No & Yes \\
Daily stairclimbing (cumulative years) & 38 & $<1$ \\
Daily knee sleeve use in affected knee (cumulative years) & $<1$ (used brace instead) & 7 \\
Kellgren-Lawrence grades at age 50-51 years & 1 (right), 0 (left) & 1 (right), 0 (left) \\
Kellgren-Lawrence grades at age 58 years & 3 bilaterally & 0 bilaterally \\
Primary location of imaging abnormalities & medial & lateral \\
Serum 25-OH vitamin D (ng/ml) & 15.0 at age 50; 44.5 at age 50 (after prescription & 24.0 at age $50 ; 53.1$ at age 56 \\
Lowest DXA bone density $T$ score & vitamin D supplements); 8.2 at age 59 & -3.0 at age 52 \\
\hline
\end{tabular}

$D X A$ dual-energy x-ray absorptiometry

structural damage in joint tissue, primarily medial in patient 1 and lateral in patient 2 .

\section{Literature search}

The PubMed/MEDLINE database was searched using the Boolean search phrase "osteoarthritis and knee and diagnostic imaging and subchondral bone and pathophysiology" to identify original research articles published from inception to March 13, 2020. These search terms were selected for their relevance to a pathophysiological model for knee osteoarthritis progression including subchondral bone (because of the reversibility/healing capacity suggested by patient 2's clinical course) and imaging markers. The search yielded 135 articles (Supplementary Appendix) of which 113 were excluded by title, abstract, or full-text review for the following reasons: study of a medical treatment, surgical study, or procedure (23), bone density or mechanical properties of bone or cartilage (19), specific patient or animal subgroup (12), posttraumatic osteoarthritis (6), or receptors, hormones, or biological markers (6); interventional study (14); test of imaging technique (7); histological or morphometric study (5); review article (14) or letter (1); non-English language (6). Twenty-two articles were eligible, of which 13 [6-18] were cited because they had the highest relevance to inform the proposed clinical model (Fig. 2). Supplemental searches were performed to expand on key topics identified in the original literature search, i.e., subchondral bone pathology [1], knee sleeves [2-5, 19-21], bone marrow lesions [22-26], clinical risk factors for knee OA progression [27-33], OA phenotypes [34], nonpharmacological treatments for OA [35-43], and clinical practice guidelines for OA management [44].

\section{Discussion}

\section{Proposed clinical model}

The authors' clinical trajectories are consistent with Lee et al.'s fluid model of osteoarthritis [6] and Aaron et al.'s report of subchondral bone circulation in knee OA [7], both based on dynamic contrast-enhanced MRI findings. As an extension of these models, our clinical model of knee osteoarthritis progression (Fig. 2) involves all fluid (including blood flow, edema, and effusion) and tissues within the knee joint and includes a modifiable early phase (KellgrenLawrence grades 0-1) in which the subchondral bone and soft tissue are capable of healing if excess fluid can be shifted out of tissue by walking. After repeated reinjury, patients transition to a nonmodifiable stage of knee OA where permanent structural damage can no longer be healed by driving out excess fluid. This permanent stage is radiographically detectable as Kellgren-Lawrence grades 2-4.

Consistent with the fluid-based clinical model, both patients experienced a feeling of fullness and pressure while they had knee joint effusions. Immediately post-injury, pain increased when the injured leg was in a dependent position and with use of a knee sleeve, presumably due to ischemic pain from fluid compression. This feeling of pressure persisted for patient 1 (who had a chronic effusion) and resolved for patient 2 (whose effusion resolved). Compared with 


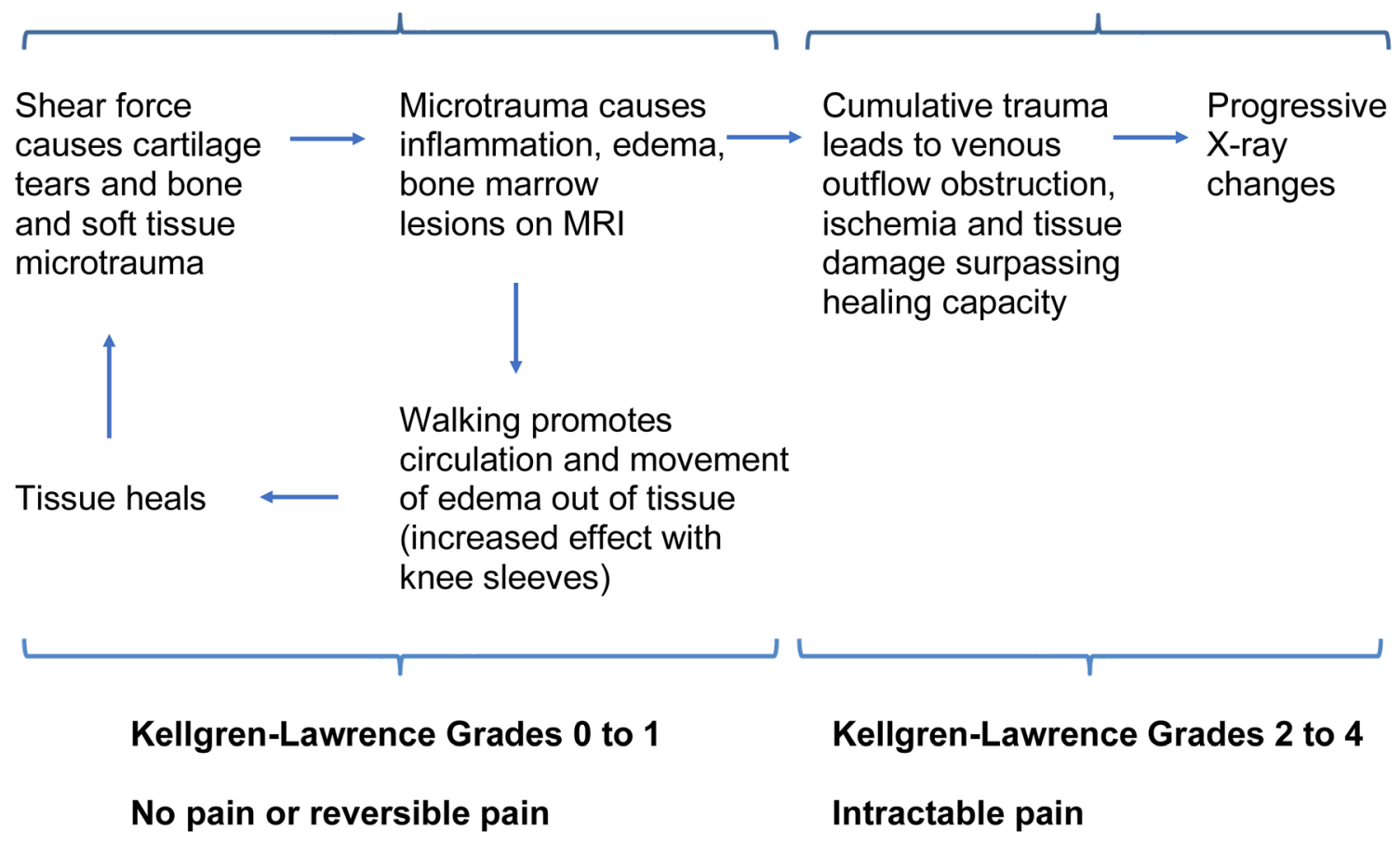

Fig. 2 Proposed clinical model of knee osteoarthritis progression

nonweight-bearing, patient 2's partial weight-bearing during healing of her subchondral fractures might have driven more fluid out of the knee joint tissues, allowing successful healing of the fractures. Later, knee sleeves might have accentuated the squeezing action of leg muscles, allowing more rapid fluid clearance as patient 2's edema regressed. In contrast, patient 1 's chronic effusion surpassed the capacity of walking to move fluid out of her knee joint tissues, promoting prolonged increased pressure within the knee joint space (similar to compartment syndrome) that led to ischemia, cell death, and permanent structural damage.

Patient 2's finger pain upon overuse of fingers (promoting mild inflammation) and upon prolonged hand rest or compression of fingers during sleep (promoting edema) is also consistent with transient OA pain associated with fluid shifts in joint tissues.

\section{Comparison with other studies}

Bone marrow lesions (sometimes called bone marrow edema) have been demonstrated to be present in individuals without $[8,22]$ and with [23] clinical OA; to wax and wane with weight-bearing activity (e.g., in marathon runners [24, 25]); and to be associated with incident knee pain in individuals at risk of OA [26], and with pain and disability for activities of daily living in patients with established OA [9]. Joint fluid overload correlates with symptoms. For example, Kornaat et al. reported that large joint effusion was associated with pain (OR, 9.99; 99\% CI 1.28, 149) and stiffness (OR, 4.67; $99 \%$ CI 1.26, 26.1), and the presence of an osteophyte in the patellofemoral compartment (OR, 2.25; 99\% CI 1.06, 4.77) was associated with pain in patients with osteoarthritis of the knee; all other imaging findings (including bone marrow edema) were not associated with symptoms in their study [10].

Budzik et al. found that subchondral bone marrow (SCBM) vascularization was greatest in the compartment most affected by $\mathrm{OA}$, both in tibia and femur, with a positive correlation between the extent of bone marrow edema and SCBM perfusion [11]. Lee et al. hypothesized that changes in perfusion patterns in subchondral bone bear a functional relationship to bone remodeling and cartilage degeneration [6]. Both Lee and Aaron emphasized venous outflow obstruction as a key mechanism of disease, where venous stasis can affect intraosseous pressure, can reduce arterial inflow, can reduce oxygen content, and may contribute to altered cell signaling in the pathophysiology of OA [7]. As described above, we incorporated these fluid dynamics as the core principles in our clinical model.

In an integrated joint system model of OA, Edd et al. described close interrelationships among cartilage thickness, gait mechanics, and subchondral bone [12]. Like their model, our model includes an early and late stage of OA during which the strength of these interrelationships may change with disease progression.

Collectively, these findings suggest a normal pattern of fluid shifts in response to low-grade inflammation associated with weight-bearing activity and injury. When an inciting injury 
causes a meniscal tear, inflammation, edema, and fluid shifts within joint tissue are usually initially reversible, and tissue can heal. If fluid overload is severe and sustained (as in patient 1), fluid compressive forces promote an ischemic state which leads to worsening irreparable structural damage, including subchondral bone attrition [13] and denudation [14] or osteonecrosis with rapid OA progression [15]. With such a model, some previously studied patient phenotypes (e.g., accelerated knee OA [16], inflammatory or bone phenotypes [34]) may represent different stages of the same pathophysiological process, with disease progression rate determined by risk factors such as female gender (e.g., different lower leg joint morphometry compared with men) [17, 27], body weight [28], joint malalignment $[13,18]$, family history (genetic tendency toward frail cartilage, obesity, or joint malalignment) [29], and possibly vitamin D deficiency [30, 31] (as for patient 1).

\section{Importance of nonpharmacological treatments}

Nonpharmacological treatments are a mainstay of OA management and can potentially help slow the progression of knee OA [35]. The most important nonpharmacological treatments used by the patients in the case studies are discussed.

\section{Lifestyle modification (weight reduction, diet, and exercise)}

An 18-month randomized controlled trial (RCT) of 454 overweight and obese adults with knee OA found a significant dose-response to weight loss; participants who lost $>10 \%$ of baseline body weight had significantly ( $p=0.0001)$ lower resultant knee forces and lower leg muscle forces than participants with less weight loss [36], and participants in diet-plusexercise and diet-only groups had more weight loss and greater reductions in IL-6 levels than those in an exercise-only group [37]. The benefits of exercise may decrease as OA severity progresses to an advanced and irreversible stage. For example, a prospective study of 1059 patients with radiographic knee $\mathrm{OA}$ at baseline found that in those with advanced disease (Kellgren-Lawrence grade 4), greater daily minutes in physical activity were associated with worsening symptoms [42].

\section{Cryotherapy and heat}

Patients may prefer heat, cold, or contrasting temperatures to alleviate OA pain $[38,39]$. According to our proposed clinical model, cryotherapy might be expected to alleviate pain by temporarily reducing blood flow to joint tissues. A systematic review of RCTs identified insufficient primary studies to draw conclusions about the effectiveness of cryotherapy on pain and physical function on individuals with knee osteoarthritis [40]. However, a review of cryotherapy treatment after unicompartmental and total knee arthroplasty concluded that continuous circulating cold flow might be optimal for pain relief and minimization of pain medication use after knee arthroplasty [41]. These findings suggest that cold therapy may be especially helpful for OA patients during periods of increased inflammation (e.g., after surgery).

\section{Knee sleeves and braces}

In patients without knee effusion, a snugly fitting elasticized knee sleeve can improve knee biomechanics [2, 19], enable surefooted walking, and minimize lower extremity edema via mild compression (below the threshold for ischemia). Consistent with our findings, knee sleeve use is associated with improved activity scores and pain scores for patients with lower Kellgren-Lawrence grades (as for patient 2) [20], while corrective or realignment braces are more effective in moderate or severe OA (patient 1) [21]. While patient 2 maintained stable Kellgren-Lawrence grade 0-1 during a 7-year period of knee sleeve use, the association between knee sleeve use and rate of radiographic OA progression has not been tested in an RCT.

\section{Conclusions and recommendations to patients}

The focus of knee osteoarthritis preventive care should be minimization of fluid accumulation in the knee joint to prevent ischemic tissue compromise that eventually leads to permanent structural damage. The broad categories of no pain versus reversible pain (resolves during nonweight-bearing) versus intractable pain are clinically useful because they correlate with smaller to larger degrees of fluid overload and imaging findings.

Based on the reported findings and the proposed clinical model, we recommend the preventive measures below for patients. These recommendations are consistent with the 2019 American College of Rheumatology/Arthritis Foundation Guideline for the Management of Osteoarthritis of the Hand, Hip, and Knee [44] and offer additional strategies for prevention and pain management based on the proposed fluid model of $\mathrm{OA}$ :

1. Lifestyle habits should be optimized to attain and maintain normal body weight [28].

2. Daily walking (ideally $\geq 6000$ steps/day) as tolerated is encouraged because it is associated with less risk of functional limitation over 2 years [43].

3. Torsion (twisting) of the knee during weight-bearing, and pushing against resistance (e.g., pushing a heavy vacuum cleaner) or while carrying a weighted load must be avoided because these activities apply shear force to the knee that can tear cartilage [33], especially in patients with genetic tendencies toward weak cartilage. 
4. Prolonged standing must be avoided because it increases lower extremity edema and (if extreme) increases the risk of subchondral fractures [1]. Patients should stand on thick rugs and commercial grade cushioned floor mats to minimize knee joint strain.

5. While stairclimbing might benefit the knee by building thigh muscle strength, frequent knee-bending activities (including stairclimbing) are associated with a higher prevalence of knee cartilage lesions and increased risk of progression of cartilage and meniscal lesions in asymptomatic middle-aged subjects [32]. Stairclimbing may be one reason patient 1 had more rapid disease progression than patient 2 .

6. Knee sleeves are a safe and effective nonpharmacological intervention for patients with early-stage knee OA [2-5, $19,20]$. However, patients with worsening pain upon use of a knee sleeve should stop use and consult a physician to rule out knee joint effusion.

7. Consistent with our extension of Aaron's [7] and Lee's [6] hypotheses regarding perfusion kinetics, vasoactive properties can be exploited for short-term knee pain relief via vasoconstriction. Cold packs should be used preferentially to minimize long-term side effects from pharmacological treatments. Patients can direct cold water onto their knees while waiting for water to warm up in the shower, and knees can be left uncovered during sleep in a cool room to decrease pain at night.

8. Hand exercise is strongly recommended for patients with hand OA [44]. Consistent with our clinical model, patients should aim for an optimal amount of hand exercise to drive excess fluid out of the fingers while avoiding overuse that can lead to inflammation. To decrease repetitive strain on fingers, the authors have used voice dictation software, a light-touch computer keyboard, plumbing fixtures with bar handles, and jars with pump dispensers that can be operated using the palm, and the handle of an eating utensil to break the seal on a jar before opening. Cold therapy should only be used for short periods on hands to avoid reduced circulation in end-organ blood vessels of the fingers.

9. Patients should consult their primary care provider if they develop intractable joint pain or a lower threshold of weight-bearing activity leading to pain, since chronic pain irreversibility may suggest permanent structural joint tissue damage.

Acknowledgments The authors thank Jordan B. Renner, MD, FACR, Professor of Radiology and Allied Health Sciences at the University of North Carolina-Chapel Hill, for evaluating the Kellgren-Lawrence grades in Fig. 1.

Authors' contributions $\mathrm{MG}$ - study concept and design, first manuscript draft, interpretation of results, critical revision of the manuscript, technical or material support. LG-study concept and design, interpretation of results, critical revision of the manuscript.

\section{Compliance with ethical standards}

Disclosures None.

Ethics approval Not applicable.

Open Access This article is licensed under a Creative Commons Attribution 4.0 International License, which permits use, sharing, adaptation, distribution and reproduction in any medium or format, as long as you give appropriate credit to the original author(s) and the source, provide a link to the Creative Commons licence, and indicate if changes were made. The images or other third party material in this article are included in the article's Creative Commons licence, unless indicated otherwise in a credit line to the material. If material is not included in the article's Creative Commons licence and your intended use is not permitted by statutory regulation or exceeds the permitted use, you will need to obtain permission directly from the copyright holder. To view a copy of this licence, visit http://creativecommons.org/licenses/by/4.0/.

\section{References}

1. Gourlay ML, Renner JB, Spang JT, Rubin JE (2015) Subchondral insufficiency fracture of the knee: a non-traumatic injury with prolonged recovery time. BMJ Case Rep 2015:bcr2015209399. https://doi.org/10.1136/bcr-2015-209399

2. Mohd Sharif NA, Goh SL, Usman J, Wan Safwani WKZ (2017) Biomechanical and functional efficacy of knee sleeves: a literature review. Phys Ther Sport 28:44-52. https://doi.org/10.1016/j.ptsp. 2017.05.001

3. Pajareya K, Chadchavalpanichaya N, Timdang S (2003) Effectiveness of an elastic knee sleeve for patients with knee osteoarthritis: a randomized single-blinded controlled trial. J Med Assoc Thail 86(6):535-542

4. Bryk FF, Jesus JF, Fukuda TY, Moreira EG, Marcondes FB, Santos MG (2011) Immediate effect of the elastic knee sleeve use on individuals with osteoarthritis. Rev Bras Reumatol 51(5):440-446

5. Coudeyre E, Nguyen C, Chabaud A, Pereira B, Beaudreuil J, Coudreuse JM, Deat P, Sailhan F, Lorenzo A, Rannou F (2018) A decision-making tool to prescribe knee orthoses in daily practice for patients with osteoarthritis. Ann Phys Rehabil Med 61(2):9298. https://doi.org/10.1016/j.rehab.2018.01.001

6. Lee JH, Dyke JP, Ballon D, Ciombor DM, Rosenwasser MP, Aaron RK (2009) Subchondral fluid dynamics in a model of osteoarthritis: use of dynamic contrast-enhanced magnetic resonance imaging. Osteoarthr Cartil 17(10):1350-1355. https://doi.org/10.1016/j. joca.2009.03.019

7. Aaron RK, Racine JR, Voisinet A, Evangelista P, Dyke JP (2018) Subchondral bone circulation in osteoarthritis of the human knee. Osteoarthr Cartil 26(7):940-944. https://doi.org/10.1016/j.joca. 2018.04.003

8. Baranyay FJ, Wang Y, Wluka AE, English DR, Giles GG, Sullivan RO, Cicuttini FM (2007) Association of bone marrow lesions with knee structures and risk factors for bone marrow lesions in the knees of clinically healthy, community-based adults. Semin Arthritis Rheum 37(2):112-118. https://doi.org/10.1016/j. semarthrit.2007.01.008

9. Sadatsuki R, Ishijima M, Kaneko H, Liu L, Futami I, Hada S, Kinoshita M, Kubota M, Aoki T, Takazawa Y, Ikeda H, Okada 
Y, Kaneko K (2019) Bone marrow lesion is associated with disability for activities of daily living in patients with early stage knee osteoarthritis. J Bone Miner Metab 37(3):529-536. https://doi.org/ 10.1007/s00774-018-0950-Z

10. Kornaat PR, Bloem JL, Ceulemans RY, Riyazi N, Rosendaal FR, Nelissen RG, Carter WO, Hellio Le Graverand MP, Kloppenburg M (2006) Osteoarthritis of the knee: association between clinical features and MR imaging findings. Radiology 239(3):811-817. https://doi.org/10.1148/radiol.2393050253

11. Budzik JF, Ding J, Norberciak L, Pascart T, Toumi H, Verclytte S, Coursier R (2017) Perfusion of subchondral bone marrow in knee osteoarthritis: a dynamic contrast-enhanced magnetic resonance imaging preliminary study. Eur J Radiol 88:129-134. https://doi.org/ 10.1016/j.ejrad.2016.12.023

12. Edd SN, Omoumi P, Andriacchi TP, Jolles BM, Favre J (2018) Modeling knee osteoarthritis pathophysiology using an integrated joint system (IJS): a systematic review of relationships among cartilage thickness, gait mechanics, and subchondral bone mineral density. Osteoarthr Cartil 26(11):1425-1437. https://doi.org/10. 1016/j.joca.2018.06.017

13. Neogi T, Nevitt M, Niu J, Sharma L, Roemer F, Guermazi A, Lewis CE, Torner J, Javaid K, Felson D (2010) Subchondral bone attrition may be a reflection of compartment-specific mechanical load: the MOST study. Ann Rheum Dis 69(5):841-844. https://doi.org/10. 1136/ard.2009.110114

14. Moisio K, Eckstein F, Chmiel JS, Guermazi A, Prasad P, Almagor O, Song J, Dunlop D, Hudelmaier M, Kothari A, Sharma L (2009) Denuded subchondral bone and knee pain in persons with knee osteoarthritis. Arthritis Rheum 60(12):3703-3710. https://doi.org/ 10.1002/art.25014

15. Satku K, Kumar VP, Chong SM, Thambyah A (2003) The natural history of spontaneous osteonecrosis of the medial tibial plateau. J Bone Joint Surg (Br) 85(7):983-988. https://doi.org/10.1302/0301620x.85b7.14580

16. Driban JB, Davis JE, Lu B, Price LL, Ward RJ, MacKay JW, Eaton CB, Lo GH, Barbe MF, Zhang M, Pang J, Stout AC, Harkey MS, McAlindon TE (2019) Accelerated knee osteoarthritis is characterized by destabilizing meniscal tears and preradiographic structural disease burden. Arthritis Rheum 71(7):1089-1100. https://doi.org/ 10.1002/art.40826

17. Pelletier JP, Raynauld JP, Berthiaume MJ, Abram F, Choquette D, Haraoui B, Beary JF, Cline GA, Meyer JM, Martel-Pelletier J (2007) Risk factors associated with the loss of cartilage volume on weight-bearing areas in knee osteoarthritis patients assessed by quantitative magnetic resonance imaging: a longitudinal study. Arthritis Res Ther 9(4):R74. https://doi.org/10.1186/ar2272

18. Mazzuca SA, Brandt KD, Lane KA, Chakr R (2011) Malalignment and subchondral bone turnover in contralateral knees of overweight/obese women with unilateral osteoarthritis: implications for bilateral disease. Arthritis Care Res 63(11):1528-1534. https://doi.org/10.1002/acr.20574

19. Schween R, Gehring D, Gollhofer A (2015) Immediate effects of an elastic knee sleeve on frontal plane gait biomechanics in knee osteoarthritis. PLoS One 10(1):e0115782. https://doi.org/10.1371/ journal.pone. 0115782

20. Marino K, Lee R, Lee P (2019) Effect of germanium-embedded knee sleeve on osteoarthritis of the knee. Orthop J Sports Med 7(10):2325967119879124. https://doi.org/10.1177/ 2325967119879124

21. Vaishya R, Pariyo GB, Agarwal AK, Vijay V (2016) Non-operative management of osteoarthritis of the knee joint. J Clin Orthop Trauma 7(3):170-176. https://doi.org/10.1016/j.jcot.2016.05.005

22. Horga LM, Hirschmann AC, Henckel J, Fotiadou A, Di Laura A, Torlasco C, D'Silva A, Sharma S, Moon JC, Hart AJ (2020) Prevalence of abnormal findings in 230 knees of asymptomatic adults using 3.0 T MRI. Skelet Radiol. https://doi.org/10.1007/ s00256-020-03394-z

23. Felson DT, Chaisson CE, Hill CL, Totterman SM, Gale ME, Skinner KM, Kazis L, Gale DR (2001) The association of bone marrow lesions with pain in knee osteoarthritis. Ann Intern Med 134(7):541-549

24. Kornaat PR, Van de Velde SK (2014) Bone marrow edema lesions in the professional runner. Am J Sports Med 42(5):1242-1246. https://doi.org/10.1177/0363546514521990

25. Horga LM, Henckel J, Fotiadou A, Hirschmann AC, Di Laura A, Torlasco C, D'Silva A, Sharma S, Moon JC, Hart AJ (2020) Is the immediate effect of marathon running on novice runners' knee joints sustained within 6 months after the run? A follow-up 3.0 T MRI study. Skelet Radiol. https://doi.org/10.1007/s00256-02003391-2

26. Felson DT, Niu J, Guermazi A, Roemer F, Aliabadi P, Clancy M, Torner J, Lewis CE, Nevitt MC (2007) Correlation of the development of knee pain with enlarging bone marrow lesions on magnetic resonance imaging. Arthritis Rheum 56(9):2986-2992. https://doi. org/10.1002/art.22851

27. Tran DH, Hoshino H, Togawa D, Matsuyama Y (2020) Characteristics of radiographic morphometries of the lower leg in subjects with progression of knee osteoarthritis in the TOEI cohort. Aging Clin Exp Res 32(1):67-76. https://doi.org/10.1007/s40520019-01164-Z

28. Wang Y, Wluka AE, Simpson JA, Giles GG, Graves SE, de Steiger RN, Cicuttini FM (2013) Body weight at early and middle adulthood, weight gain and persistent overweight from early adulthood are predictors of the risk of total knee and hip replacement for osteoarthritis. Rheumatology (Oxford) 52(6):1033-1041. https:// doi.org/10.1093/rheumatology/kes419

29. Pan F, Blizzard L, Tian J, Cicuttini F, Winzenberg T, Ding C, Jones $G$ (2017) The interaction between weight and family history of total knee replacement with knee cartilage: a 10-year prospective study. Osteoarthr Cartil 25(2):227-233. https://doi.org/10.1016/j.joca. 2016.10 .013

30. Zhang FF, Driban JB, Lo GH, Price LL, Booth S, Eaton CB, Lu B, Nevitt M, Jackson B, Garganta C, Hochberg MC, Kwoh K, McAlindon TE (2014) Vitamin D deficiency is associated with progression of knee osteoarthritis. J Nutr 144(12):2002-2008. https://doi.org/10.3945/jn.114.193227

31. Yu Y, Liu D, Feng D, Zhao J (2020) Association between vitamin D and knee osteoarthritis: a PRISMA-compliant meta-analysis. Z Orthop Unfall. https://doi.org/10.1055/a-1098-8815

32. Virayavanich W, Alizai H, Baum T, Nardo L, Nevitt MC, Lynch JA, McCulloch CE, Link TM (2013) Association of frequent knee bending activity with focal knee lesions detected with $3 \mathrm{~T}$ magnetic resonance imaging: data from the osteoarthritis initiative. Arthritis Care Res 65(9):1441-1448. https://doi.org/10.1002/acr.22017

33. Pathria MN, Chung CB, Resnick DL (2016) Acute and stressrelated injuries of bone and cartilage: pertinent anatomy, basic biomechanics, and imaging perspective. Radiology 280(1):21-38. https://doi.org/10.1148/radiol.16142305

34. Deveza LA, Melo L, Yamato TP, Mills K, Ravi V, Hunter DJ (2017) Knee osteoarthritis phenotypes and their relevance for outcomes: a systematic review. Osteoarthr Cartil 25:1926-1941. https://doi.org/10.1016/j.joca.2017.08.009

35. Migliore A, Gigliucci G, Alekseeva L, Avasthi S, Bannuru RR, Chevalier X, Conrozier T, Crimaldi S, Damjanov N, de Campos GC, Diracoglu D, Herrero-Beaumont G, Iolascon G, Ionescu R, Isailovic N, Jerosch J, Lains J, Maheu E, Makri S, Martusevich N, Matucci Cerinc M, Micu M, Pavelka K, Petrella RJ, Tarantino U, Raman R (2019) Treat-to-target strategy for knee osteoarthritis. International technical expert panel consensus and good clinical practice statements. Ther Adv Musculoskelet Dis 11: 1759720X19893800. https://doi.org/10.1177/1759720X19893800 
36. Messier SP, Beavers DP, Mihalko SL, Miller GD, Lyles MF, Hunter DJ, Carr JJ, Eckstein F, Guermazi A, Loeser RF, DeVita P (2020) The effects of intensive dietary weight loss and exercise on gait in overweight and obese adults with knee osteoarthritis. The Intensive Diet and Exercise for Arthritis (IDEA) trial. J Biomech 98:109477. https://doi.org/10.1016/j.jbiomech.2019.109477

37. Messier SP, Mihalko SL, Legault C, Miller GD, Nicklas BJ, DeVita P, Beavers DP, Hunter DJ, Lyles MF, Eckstein F, Williamson JD, Carr JJ, Guermazi A, Loeser RF (2013) Effects of intensive diet and exercise on knee joint loads, inflammation, and clinical outcomes among overweight and obese adults with knee osteoarthritis: the IDEA randomized clinical trial. JAMA 310(12):1263-1273. https://doi.org/10.1001/jama.2013.277669

38. Yildirim N, Filiz Ulusoy M, Bodur H (2010) The effect of heat application on pain, stiffness, physical function and quality of life in patients with knee osteoarthritis. J Clin Nurs 19(7-8):11131120. https://doi.org/10.1111/j.1365-2702.2009.03070.x

39. Denegar CR, Dougherty DR, Friedman JE, Schimizzi ME, Clark JE, Comstock BA, Kraemer WJ (2010) Preferences for heat, cold, or contrast in patients with knee osteoarthritis affect treatment response. Clin Interv Aging 5:199-206. https://doi.org/10.2147/cia. s11431

40. Dantas LO, Moreira RFC, Norde FM, Mendes Silva Serrao PR, Alburquerque-Sendin F, Salvini TF (2019) The effects of cryotherapy on pain and function in individuals with knee osteoarthritis: a systematic review of randomized controlled trials. Clin Rehabil 33(8):1310-1319. https://doi.org/10.1177/0269215519840406
41. Chughtai M, Sodhi N, Jawad M, Newman JM, Khlopas A, Bhave A, Mont MA (2017) Cryotherapy treatment after unicompartmental and total knee arthroplasty: a review. J Arthroplast 32(12):38223832. https://doi.org/10.1016/j.arth.2017.07.016

42. Liu SH, Driban JB, Eaton CB, McAlindon TE, Harrold LR, Lapane KL (2016) Objectively measured physical activity and symptoms change in knee osteoarthritis. Am J Med 129(5):497-505 e491. https://doi.org/10.1016/j.amjmed.2015.12.029

43. White DK, Tudor-Locke C, Zhang Y, Fielding R, LaValley M, Felson DT, Gross KD, Nevitt MC, Lewis CE, Torner J, Neogi T (2014) Daily walking and the risk of incident functional limitation in knee osteoarthritis: an observational study. Arthritis Care Res 66(9):1328-1336. https://doi.org/10.1002/acr.22362

44. Kolasinski SL, Neogi T, Hochberg MC, Oatis C, Guyatt G, Block J, Callahan L, Copenhaver C, Dodge C, Felson D, Gellar K, Harvey WF, Hawker G, Herzig E, Kwoh CK, Nelson AE, Samuels J, Scanzello C, White D, Wise B, Altman RD, DiRenzo D, Fontanarosa J, Giradi G, Ishimori M, Misra D, Shah AA, Shmagel AK, Thoma LM, Turgunbaev M, Turner AS, Reston J (2020) 2019 American College of Rheumatology/Arthritis Foundation guideline for the management of osteoarthritis of the hand, hip, and knee. Arthritis Rheum 72(2):220-233. https://doi. org/10.1002/art.41142

Publisher's note Springer Nature remains neutral with regard to jurisdictional claims in published maps and institutional affiliations. 